\title{
Heparin-Binding Epidermal Growth Factor-Like Growth Factor Is a Potent Neurotrophic Factor for PC12 Cells
}

\author{
Yu Zhou Gail E. Besner \\ Department of Pediatric Surgery, Research Institute at Nationwide Children's Hospital, Center for Perinatal \\ Research, Nationwide Children's Hospital, Ohio State University College of Medicine, Columbus, Ohio, USA
}

\begin{abstract}
Key Words
Heparin-binding epidermal growth factor-like growth factor $\cdot$ PC12 cells - Neurite outgrowth - Oxygen glucose deprivation $\cdot$ Mitogen-activated protein kinase signaling pathway
\end{abstract}

\begin{abstract}
Heparin-binding epidermal growth factor EGF-like growth factor (HB-EGF) is a member of the epidermal growth factor family that is expressed in many cell types. We have previously reported the effects of HB-EGF on intestinal epithelial cells and endothelial cells after exposure to ischemia/reperfusion in vivo or anoxia/reoxygenation injury in vitro. However, the effect of HB-EGF on neuronal cells is largely unexplored. In this study, we examined the effect of HB-EGF on neurite outgrowth in pheochromocytoma (PC12) cells as well as the neuroprotective effect of HB-EGF on injured PC12 cells exposed to oxygen and glucose deprivation (OGD), which mimics ischemic conditions. We found that HB-EGF significantly promotes PC12 cell neurite outgrowth and that this effect was blocked by EGF receptor (EGFR) inhibition or mitogen-activated protein kinase (MAPK) inhibition, but not by tyrosine kinase inhibition. In the face of OGD injury, HB-EGF preserves cell viability and decreases apoptosis and LDH release in PC12 cells. HB-EGF-mediated cytoprotection was abolished by EGFR inhibition and MAPK inhibition. We conclude that HB-EGF, through its interaction with the EGF receptor, activates the MAPK signaling path-
\end{abstract}

way in PC12 cells under basal or injury conditions, leading to enhanced neurite outgrowth and neuroprotection against ischemic injury.

Copyright $\odot 2010$ S. Karger AG, Basel

\section{Introduction}

Heparin-binding epidermal growth factor-like growth factor (HB-EGF) was first identified in the conditioned medium of cultured human macrophages [1] and was found to be a member of the epidermal growth factor (EGF) family [2]. It is synthesized as a 208-amino-acid transmembrane precursor protein (proHB-EGF), which is enzymatically cleaved extracellularly to yield a 14 - to 20-kDa, 86-amino-acid soluble growth factor (sHB-EGF) $[3,4]$. HB-EGF is a potent mitogenic and chemoattractant protein for many cell types. While the mitogenic function of sHB-EGF is mediated through activation of the EGF receptor (EGFR, ErbB1) [5], its migration-inducing function involves the activation of ErbB4 [6] and $\mathrm{N}$-arginine dibasic convertase [7], a specific HB-EGF receptor. In addition, HB-EGF is a biologically active protein that can bind to heparan sulfate proteoglycans [8], and can form complexes with other membrane proteins including CD9 [9] and integrin $\alpha 3 \beta 1$ [10]. Such protein-protein interactions enhance the biological activity of HB-EGF. HBEGF can bind directly to the antiapoptotic BAG-1 protein [11] and may function as a survival protein [12]. 
HB-EGF is widely distributed in neurons and glial cells throughout the brain, where it is expressed in both prenatal and postnatal rats [13]. It specifically induces cortical neuronal migration during the development of the brain $[13,14]$. Moreover, expression of HB-EGF is significantly increased in response to tissue damage [15], hypoxia $[16,17]$ and oxidative stress $[18,19]$, and also during wound healing and regeneration [20, 21]. HB-EGF has been shown to restore neurogenesis in neuron degenerative disorders and in ischemia-induced brain injury $[16,22$, 23]. HB-EGF enhances the survival of dopaminergic neurons by activation of the mitogen-activated protein kinase (MAPK) and the Akt signal pathway [14]. We have recently shown that deletion of the HB-EGF gene causes significant neuronal cell loss and hypertrophied nerve fibers in the intestinal myenteric nervous system [unpublished data]. These observations suggest that HB-EGF plays a potential role in neurogenesis in the gastrointestinal tract.

The PC12 cell line, derived from rat pheochromocytoma cells, has been extensively used as an in vitro model system to investigate neuronal differentiation and ischemic disorders. Neuronal differentiation refers to the physiological, biochemical and morphological changes that cells undergo in order to become mature neurons [24]. Neurotrophins such as nerve growth factor (NGF) have been shown to induce PC12 cell differentiation characterized by cell cycle arrest, neurite outgrowth and the emergence of differentiation markers $[25,26]$. Growth factor-induced neurite outgrowth is accompanied by enhanced activation of the Ras-MEK-Erk cascade [27, 28]. In addition, activation of the MAPK signaling pathway protects neuronal cells from ischemic injury by inhibiting apoptosis and promoting cell survival [29]. In the current study, we examined the ability of HB-EGF to affect PC12 cell differentiation as determined by neurite outgrowth in these cells. We also investigated the neuroprotective effect of HB-EGF on PC12 cells exposed to injury using a model of oxygen and glucose deprivation (OGD) to mimic ischemic conditions.

\section{Materials and Methods}

\section{Cell Culture}

The PC12 cell line was purchased from the American Type Culture Collection (ATCC, Manassas, Va., USA). Cells were maintained in Dulbecco's Modified Eagle Medium (DMEM; Invitrogen, Carlsbad, Calif., USA) supplemented with $10 \%$ fetal bovine serum, $100 \mathrm{U} / \mathrm{ml}$ penicillin and $100 \mu \mathrm{g} / \mathrm{ml}$ streptomycin at $37^{\circ} \mathrm{C}$ in $5 \% \mathrm{CO}_{2}$. All experiments were performed on cells between passages $4-10$. Recombinant human mature HB-EGF used in all experiments was produced in Pichia pastoris yeast and supplied to us by Trillium Therapeutics, Inc. (Toronto, Canada).

\section{Neurite Outgrowth Measurement}

To measure neurite outgrowth, $4 \times 10^{3} \mathrm{PC} 12$ cells were seeded in each well of an 8-well culture slide chamber coated with poly-D-lysine and laminin (BD Biosciences, Bedford, Mass., USA) and starved with serum-free DMEM for $16 \mathrm{~h}$. After addition of HB-EGF (20 ng/ml) to the cells, cells were incubated for an additional 24 and $72 \mathrm{~h}$, and random photographs were taken for quantification of neurite outgrowth. Other agents, such as AG1478 ( $1 \mu \mathrm{mol}$; selective EGF receptor kinase inhibitor; Cayman Chemical, Ann Arbor, Mich., USA), monoclonal antibody against the ErbB4 extracellular domain (MAb-3, clone H72.8, $30 \mu \mathrm{g} / \mathrm{ml}$; NeoMarker, Feremont, Calif., USA), PD98059 (20 $\mu$ mol; selective inhibitor of MAP kinase kinase; Calbiochem, Gibbstown, N.J., USA), U0126 (10 $\mu \mathrm{mol}$; selective inhibitor of Erk1/2; Calbiochem), LY294002 (50 $\mu \mathrm{mol}$; inhibitor of the phosphoinositide 3-kinase, PI3K, pathway; Calbiochem) or K252a (1 $\mu \mathrm{mol}$; Trk tyrosine kinase receptor inhibitor; Sigma-Aldrich, St. Louis, Mo., USA), were added $30 \mathrm{~min}$ prior to HB-EGF treatment. The proportion of neurite-bearing cells was counted using an inverted microscope and phase contrast microscopy. Cell processes longer than the cell body diameter were counted as neurites, with neurites identified and counted in 100 cells per photograph. Three independent experiments were performed.

To investigate whether neurite outgrowth was specifically induced by HB-EGF, HB-EGF (20 ng/ $\mathrm{ll}$ ) was pre-incubated with neutralizing HB-EGF antibodies $(1 \mu \mathrm{g} / \mu \mathrm{l}$; R\&D Systems Inc., Minneapolis, Minn., USA) for $60 \mathrm{~min}$ at $37^{\circ} \mathrm{C}$, and then the neutralized $\mathrm{HB}-\mathrm{EGF}$ was added to the medium in the PC12 neurite outgrowth assay.

\section{Western Blot Analysis}

PC12 cell lysates were subjected to SDS-PAGE and proteins were transferred to nitrocellulose membranes and subjected to immunoblot analysis. The levels of total and phospho-Erk1/2 were detected using total- and phospho-specific primary antibodies followed by HRP-conjugated secondary antibodies. Blots were developed with the ECL Plus system (Amersham Biosciences, Piscataway, N.J., USA) using Hyperfilm (Amersham Biosciences) for exposure. The intensity of immunoreative bands on Western blots was quantified using the Scion Image Program (Scion Corporation, Frederick, Md., USA) and expressed as means \pm SEM

\section{Ras and Rap1 Activation Assay}

Ras and Rap1 GTP loading were measured using Ras and Rap1 activation assay kits (Millipore, Kankakee, Ill., USA) according to previously described methodology [30]. PC12 cells were grown in culture to about $90 \%$ confluence and stimulated with HB-EGF (20 $\mathrm{ng} / \mathrm{ml}$ ). Cells were rinsed in ice-cold TBS and solubilized at $4^{\circ} \mathrm{C}$ for $10 \mathrm{~min}$ in lysis buffer. Lysates were clarified by centrifugation, and supernatants were collected and incubated with glutathioneSepharose beads coupled to C-RafRBD/GST to isolate RasGTP, or RalGDSRBD/GST to isolate Rap1GTP. Protein complexes were allowed to form for $1 \mathrm{~h}$ at $4^{\circ} \mathrm{C}$ and precipitates were washed three times with lysis buffer. Finally, precipitates were resuspended in Laemmli sample buffer, and denatured proteins were subjected to SDS-PAGE followed by Western blot analysis with anti-Ras or an- 
ti-Rap1 antibodies. $\beta$-Actin was used as a measure of equal protein loading.

\section{Fluorescence Immunohistochemistry}

PC12 cells were seeded in 8-well culture slides coated with poly-D-lysine/laminin and were incubated with or without HBEGF $(20 \mathrm{ng} / \mathrm{ml})$. After $24 \mathrm{~h}$, cells were fixed with $4 \%$ paraformaldehyde in $0.1 \mathrm{M}$ PBS for $30 \mathrm{~min}$, and blocked with $10 \%$ goat serum, $0.1 \%$ Triton X-100/PBS for $30 \mathrm{~min}$. After incubation with primary antibody (anti-microtubule-associated protein $1 \mathrm{~b}, \mathrm{MAP} 1 \mathrm{~b}, \mathrm{mAb}$; Sigma-Aldrich) for $2 \mathrm{~h}$, cells were rinsed with PBS and incubated with Cy2-labeled secondary antibody (Molecular Probes, Billerica, Mass., USA) for $1 \mathrm{~h}$. Propidium iodide (PI; Invitrogen) was used to visualize nuclei. Fluorescent staining was examined using a Zeiss AxioSkop 2 Plus microscope (Carl Zeiss Inc., Thornwood, N.Y., USA).

\section{OGD of PC12 Cells}

PC12 cells were plated at a density of $1 \times 10^{5}$ cells/well in 6 -well plates precoated with poly-D-lysine/laminin and grown at $37^{\circ} \mathrm{C}$ in a normoxic, $5 \% \mathrm{CO}_{2}$ atmosphere. For the induction of OGD, cells were washed twice in DMEM without glucose (Life Technologies, Carlsbad, Calif., USA), switched to DMEM without glucose supplemented with $1 \%$ FBS (OGD medium), and placed in modular incubator chambers (Billups-Rothenberg, Del Mar, Calif., USA). The chambers were flushed with a gas mixture of $95 \% \mathrm{~N}_{2} / 5 \% \mathrm{CO}_{2}$ for $30 \mathrm{~min}$ at room temperature at 3 liters $/ \mathrm{min}$. Oximetry was used to confirm that the oxygen concentration in the chamber was $<0.1 \%$. After flushing, chambers were sealed and placed at $37^{\circ} \mathrm{C}$. OGD was carried out for $3 \mathrm{~h}$, after which addition of glucose $(4.5 \mathrm{~g} / \mathrm{l})$ and restoration of oxygen levels to preinjury conditions were performed for an additional $21 \mathrm{~h}$. Some cells received HB-EGF (20 ng/ml) beginning $16 \mathrm{~h}$ prior to OGD. Chemical inhibitors such as AG1478 or PD98056 were added 30 min prior to addition of HB-EGF.

\section{Flow Cytometric Analysis of PC12 Cell Apoptosis}

PC12 cell apoptosis was assessed using the Vybrant Apoptosis Assay (Invitrogen). Cells were seeded in 100-mm culture dishes coated with poly-D-lysine/laminin at a density of $1 \times 10^{6}$ cells/ well. After $12 \mathrm{~h}$ of low-serum (1\% FBS) starvation, some cells were pretreated with HB-EGF $(20 \mathrm{ng} / \mathrm{ml})$ for $16 \mathrm{~h}$ prior to OGD injury. Twenty-four hours after OGD injury, cells attached to the plates and floating dead cells were harvested and resuspended in binding buffer. FITC-annexin $\mathrm{V}(1 \mathrm{mg} / \mathrm{ml})$ was then added to the resuspended cells with incubation for $10 \mathrm{~min}$ at $37^{\circ} \mathrm{C}$. Cells were resuspended in PI solution and incubated in the dark for $30 \mathrm{~min}$ at room temperature. Stained cells were analyzed using a BD LSR II flow cytometer (BD Biosciences, San Jose, Calif., USA). Chemical inhibitors (AG1478, PD98059) were added to the culture medium 30 min prior to HB-EGF treatment.

\section{Lactate Dehydrogenase Assay for PC12 Cell Damage}

PC12 cell damage after OGD injury was also quantitatively assessed by the measurement of lactate dehydrogenase (LDH) using an LDH assay kit (Sigma-Aldrich). Efflux of LDH occurring from either necrotic or apoptotic cells is proportional to the number of neurons damaged or destroyed. Briefly, $50 \mu \mathrm{l}$ of supernatant from each well was transferred to a 96-well plate, LDH $(100 \mu \mathrm{l}) \mathrm{LDH}$ assay mixture was added to each sample, and the plates were in- cubated for $30 \mathrm{~min}$ at room temperature. The reaction was then stopped and absorbance was read at $490 \mathrm{~nm}$ with an ELX 800UV microtiter plate reader (Bio-Tek Instruments Inc., Winooski, Vt., USA). For the assessment of total LDH activity, cells were incubated with $100 \mu \mathrm{l}$ of lysis solution/well for $30 \mathrm{~min}$ at $37^{\circ} \mathrm{C}$ and lysates were centrifuged to remove cellular debris. $\mathrm{LDH}$ release was expressed as a percentage of the total LDH (cellular plus medium LDH), which represents the proportion of cell death caused by OGD.

\section{MTT Assay of PC12 Cell Viability}

PC12 cell viability was assessed by measurement of the reduction of 3-(4,5-dimethylthiazol-2-yl)-2,5-diphenyltetrazolium bromide (MTT) to produce a dark blue formazan product. PC12 cells were seeded in 96 well plates at a density of $1 \times 10^{5}$ cells/well, exposed to OGD injury as described above, and MTT added to each well with incubation for $4 \mathrm{~h}$ at $37^{\circ} \mathrm{C}$ according to the manufacturer's instructions (Cayman Chemical). Absorbance was read at $570 \mathrm{~nm}$ to quantify the formazan reaction product. Results were expressed as the percent of absorbance of normoxic control cells.

\section{Statistic Analysis}

All values were expressed as means \pm SEM. Statistical significance was determined by one-way ANOVA with $p<0.05$ or $\mathrm{p}<0.01$ considered statistically significant.

\section{Results}

\section{HB-EGF Induces PC12 Cell Neurite Outgrowth}

Neurite outgrowth represents a morphological change in neuronal tissue that results in synapse formation both during development and during the axon path finding that occurs after nerve injury [31]. We first examined the ability of HB-EGF to affect neurite outgrowth in PC12 cells. We found that HB-EGF induced PC12 cell differentiation, as demonstrated by significant neurite outgrowth extension as early as 1 day after HB-EGF addition (fig. 1a). We next investigated whether HB-EGF-induced neurite outgrowth in PC12 cells was dependent upon activation of the EGFR. We pretreated PC12 cells with the EGFR inhibitor AG1478 30 min prior to HB-EGF stimulation. We found that HB-EGF-induced neurite outgrowth was significantly inhibited by the addition of AG1478 (fig. 1a). On the other hand, blockage of the ErbB4 receptor subtype using a neutralizing monoclonal antibody did not alter HB-EGF-induced neurite outgrowth. In addition, blockage of Trk tyrosine kinase receptor activation with K252a did not reduce the effect of HB-EGF on neurite outgrowth (fig. 1a). Since activation of the MAPK pathway has been reported to play a critical role in neuronal cell differentiation after growth factor stimulation, we next tested whether HB-EGF-induced neurite outgrowth was dependent on the MAPK pathway. The Erk kinase 

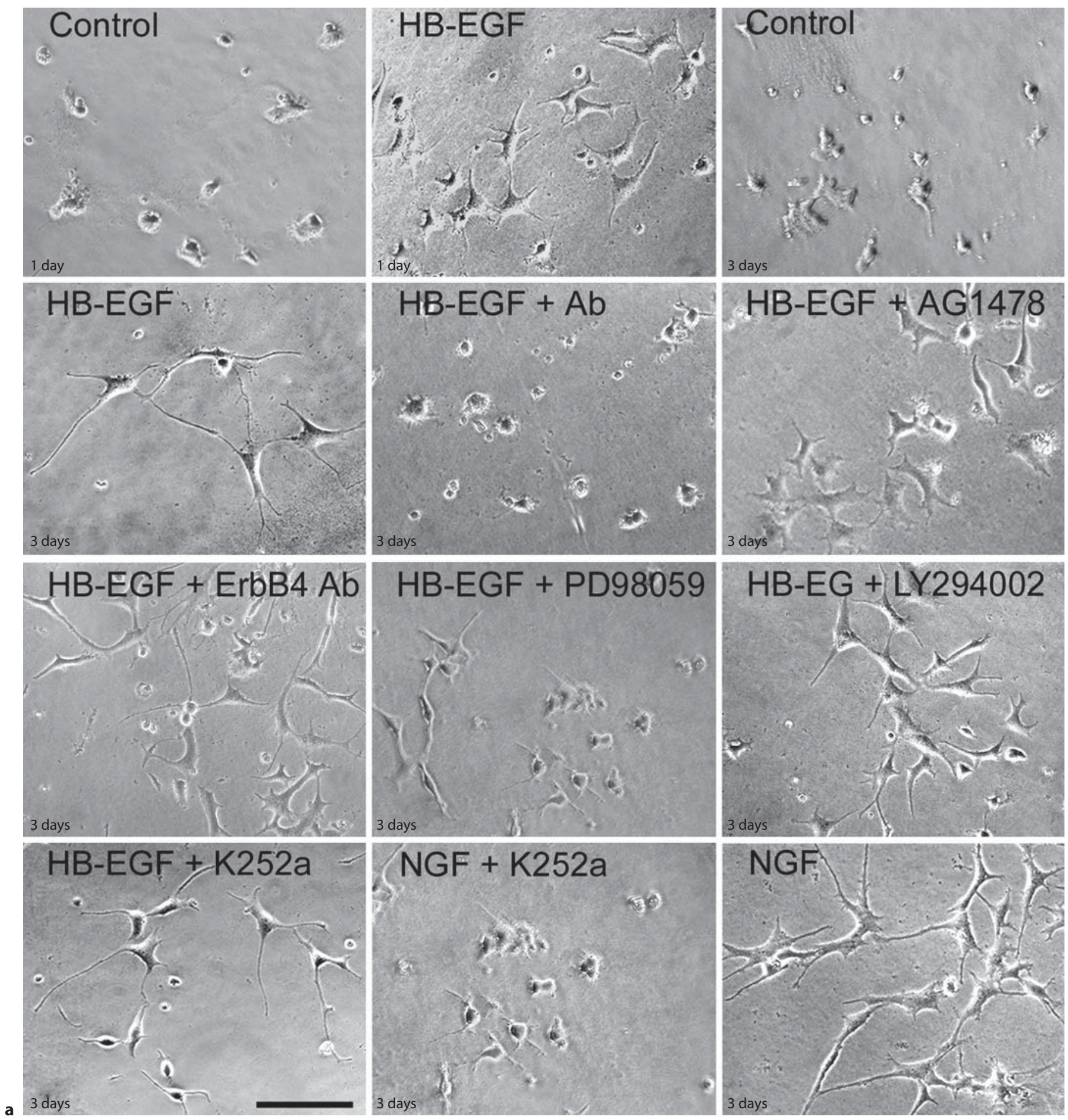

Fig. 1. HB-EGF-induced neurite outgrowth in PC12 cells. a Changes in cell shape and neurite outgrowth induced by HBEGF and NGF. PC12 cells were grown on 8-well cell culture slides at a density of $4 \times 10^{3}$ cells/well in the presence or absence of HBEGF (20 ng/ml) for 1 or 3 days, or in the presence of NGF (50 ng/ $\mathrm{ml}$ ) for 3 days. AG1478 (EGFR inhibitor), ErbB4 neutralizing antibody, PD98059 (MAPK inhibitor), LY294002 (PI3K inhibitor) or K252a (Trk tyrosine kinase receptor inhibitor) were added to the culture medium $30 \mathrm{~min}$ prior to HB-EGF or NGF addition. Scale bar $=100 \mu \mathrm{m}$. 


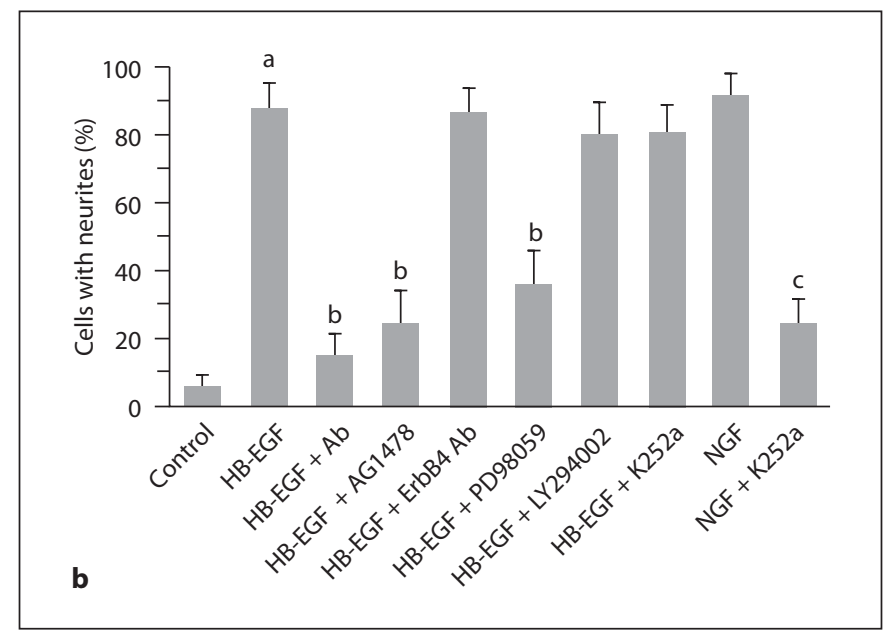

Fig. 1. HB-EGF-induced neurite outgrowth in PC12 cells. b Quantification of neurite extension. The percentage of cells with at least one neurite longer than the cell body diameter was determined 3 days after stimulation. c Dose-dependent response of PC12 cells to HB-EGF-mediated neurite outgrowth. PC12 cells were treated with increasing concentrations of HB-EGF for 3

inhibitor PD98059 markedly reduced HB-EGF-induced neurite outgrowth (fig. 1a). Similar to the effects of PD98059, MAPK inhibition with U0126 significantly blocked HB-EGF-induced neurite outgrowth as well (data not shown). These observations suggest that activation of MAPK is crucial for HB-EGF-induced neurite outgrowth. However, the PI3K inhibitor LY2942002 did not compromise the effect of HB-EGF on PC12 neurite outgrowth (fig. 1a).

To quantify neurite extension, we counted differentiated PC12 cells containing at least one dendrite longer than the cell body after a 3-day incubation in the presence or absence of HB-EGF. Compared to non-HB-EGF-treated control cells, substantial neurite outgrowth was observed in HB-EGF treated PC12 cells ( $87.8 \pm 7.9$ vs. 5.8 $\pm 3.6 \%$; $<$ <.01) (fig. 1b). AG1478 and PD98059 significantly reduced the rate of neurite extension induced by HB-EGF to $24.3 \pm 9.6$ and $35.8 \pm 9.55 \%$, respectively, while K252a or LY2942002 had no effect, suggesting that HB-EGF-induced neurite outgrowth was dependent upon EGFR activation and the MAPK pathway rather than the Trk tyrosine kinase or PI3K pathways. Of particular note is that the Trk tyrosine kinase pathway has been reported to be activated in differentiated PC12 cells stimulated by NGF.

The effect of HB-EGF on neurite outgrowth in PC12 cell was found to be dose dependent (fig. 1c). After a 3-day

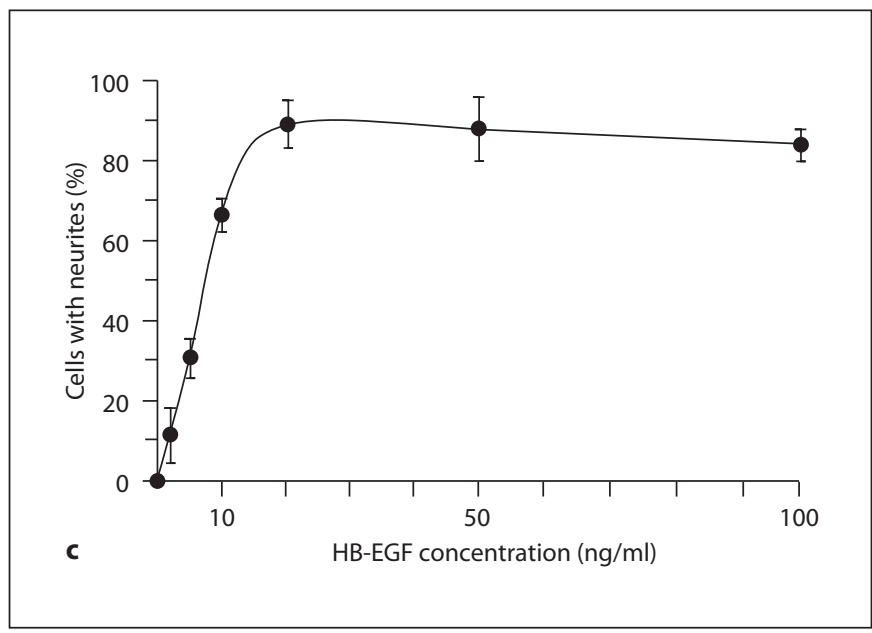

days. Cells containing at least one neurite that was longer than the cell body diameter were counted, and the percentage of cells with neurites was determined. Values shown are mean \pm SEM of about 100 cells obtained from three independent experiments. ${ }^{a} \mathrm{p}<0.01$ vs. control; ${ }^{\mathrm{b}} \mathrm{p}<0.01$ vs. HB-EGF; ${ }^{\mathrm{c}} \mathrm{p}<0.01$ vs. NGF.

incubation with HB-EGF, maximal neurite extension was observed with addition of $20 \mathrm{ng} / \mathrm{ml} \mathrm{HB}$-EGF.

\section{HB-EGF Increases MAP1b Protein Expression in PC12 Cells}

MAP1b is a neuronal cytoskeletal marker with predominant expression in the developing nervous system that is frequently used as a marker for neuronal cell sprouting [32-35]. PC12 cells were treated with HB-EGF $(20 \mathrm{ng} / \mathrm{ml})$ for $24 \mathrm{~h}$, followed by immunocytochemical detection of MAP1b using anti-MAP1b monoclonal antibodies. We found that HB-EGF significantly increased MAP1b immunostaining in the cytoplasm and dendrites of PC12 cells (fig. 2). The elevated protein expression of MAP1b confirms that HB-EGF promotes neuronal differentiation of PC12 cells.

\section{HB-EGF Increases MAPK Activation in PC12 Cells}

MAPK activation is necessary for growth factor-induced neurite outgrowth in PC12 cells [36]. Activation of the MAPK pathway is involved in the reorganization of microtubules towards the future direction of neurite outgrowth under normal conditions and after cellular injury $[37,38]$. Since HB-EGF-induced neurite outgrowth was inhibited by PD98059 (fig. 1b), we next confirmed the role of MAPK activation using immunoblot analysis to examine the ability of HB-EGF to affect phosphorylation of 
Fig. 2. Effect of HB-EGF on MAP1b protein production. Representative photo-micrographs of PC12 cell MAP1b immunostaining using anti-MAP1b antibodies (green) after a 24-hour incubation with HB-EGF (a) or without (b) $(20 \mathrm{ng} / \mathrm{ml})$. Cells were costained with PI (red) to demonstrate nuclear staining. Scale bar $=100$ $\mu \mathrm{m}$.

Fig. 3. HB-EGF-induced activation of ERK, Ras and Rap1 in PC12 cells under noninjury conditions. a PC12 cells grown at a density of $1 \times 10^{5}$ cells/well were serum starved by incubation with DMEM with $1 \% \mathrm{FBS}$ for $12 \mathrm{~h}$. Cells were then stimulated with HB-EGF $(20 \mathrm{ng} / \mathrm{ml})$ for the indicated times. Cell lysates were separated by SDS-PAGE and analyzed by immunoblotting. Activated MAPK was specifically recognized by a rabbit anti-phosphorylated Erk1/2 antibody. The blot was then reprobed with a rabbit antibody to total Erk1/2. To detect activated Ras and Rap, lysates were clarified by centrifugation, and supernatants were collected and incubated with glutathione-Sepharose beads coupled to C-RafRBD/GST or RalGDSRBD/GST. After incubation, the samples were separated by SDS-PAGE and analyzed by Western blotting with mouse anti-Ras or anti-Rapl antibodies. b-e The intensity of immunoreative bands on Western blots was quantified as follows: the band intensity ratios of phosphorylated Erk1/2 to total Erk1/2 (b, c), Ras to $\beta$ actin (d) and Rap to $\beta$-actin (e) were calculated and expressed as means \pm SEM. Data were obtained from at least three independent experiments. ${ }^{*} \mathrm{p}<0.05$ vs. no HB-EGF treatment.
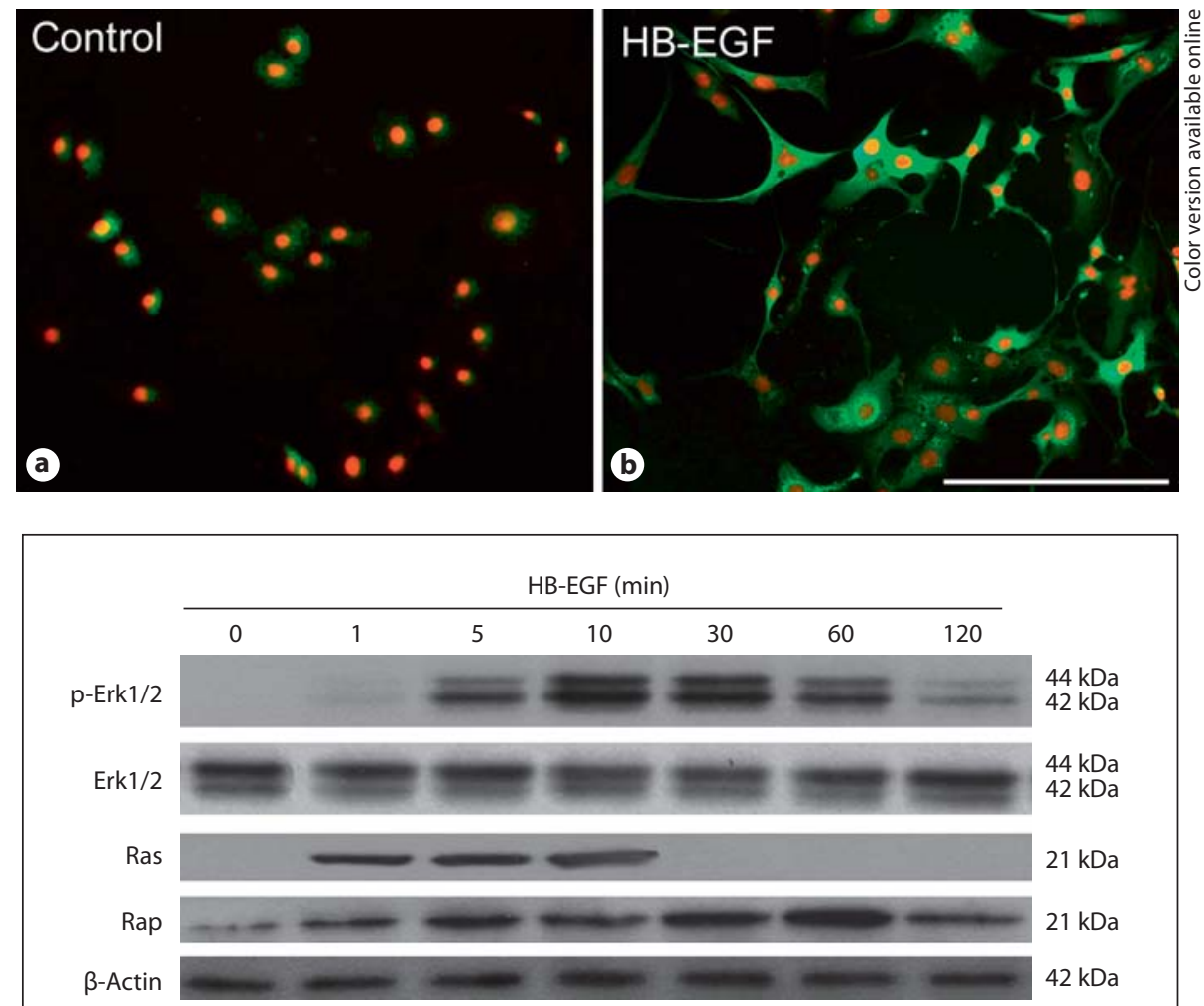

a
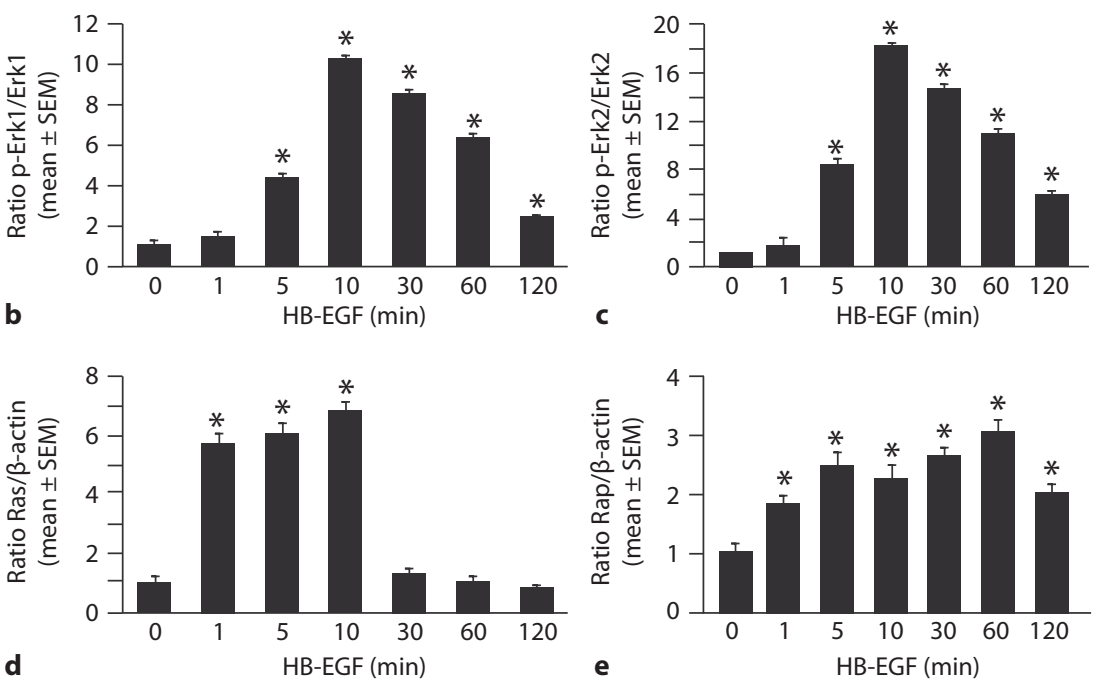

Erk1/2. The induction of phosphorylation of Erk1/2 by HB-EGF appeared at $1 \mathrm{~min}$, peaked at $10-30 \mathrm{~min}$, and lasted for at least for $2 \mathrm{~h}$ (fig. 3). This pattern of Erk activation is similar to NGF-induced Erk signaling in PC12 cells [39]. Two distinct pathways are involved in the activation of Erk: the small G protein Ras is required for the initial activation of Erk and the small G protein Rap1 is required for the sustained activation of Erk [40, 41]. Therefore, we next investigated whether HB-EGF activates Ras and Rap1 in PC12 cells. Ras activation was detected within 1 min after HB-EGF stimulation, lasted for $10 \mathrm{~min}$, and then dramatically decreased thereafter. Rap1 
Fig. 4. HB-EGF-induced activation of ERK in PC12 cells exposed to OGD injury. PC12 cells were pretreated with AG1478 $(1 \mu \mathrm{mol})$ or PD98059 $(20 \mu \mathrm{mol})$ prior to incubation of the cells with HB-EGF (20 $\mathrm{ng} / \mathrm{ml}$ ) for $16 \mathrm{~h}$. Some cells received neutralized HB-EGF by preincubating HBEGF (20 ng/ $\mu \mathrm{l})$ with neutralizing HB-EGF antibodies $(1 \mu \mathrm{g} / \mu \mathrm{l})$ for $60 \mathrm{~min}$ at $37^{\circ} \mathrm{C}$. Cells were then exposed to OGD for $3 \mathrm{~h}$ followed by return to normoxia and normal glucose levels for $21 \mathrm{~h}$. Cell lysates were then collected for evaluation of Erk activation by immunoblotting using antiphospho Erk1/2. Pan-Erk1/2 was used to verify equal protein loading in all lanes. The intensity of immunoreactive bands on Western blots was quantified as follows: the band intensity ratio of phosphorylated Erk1/2 to total Erk1/2 was calculated and expressed as the mean \pm SEM. Data were obtained from at least three independent experiments. ${ }^{*} \mathrm{p}<0.05$ vs. normoxia.

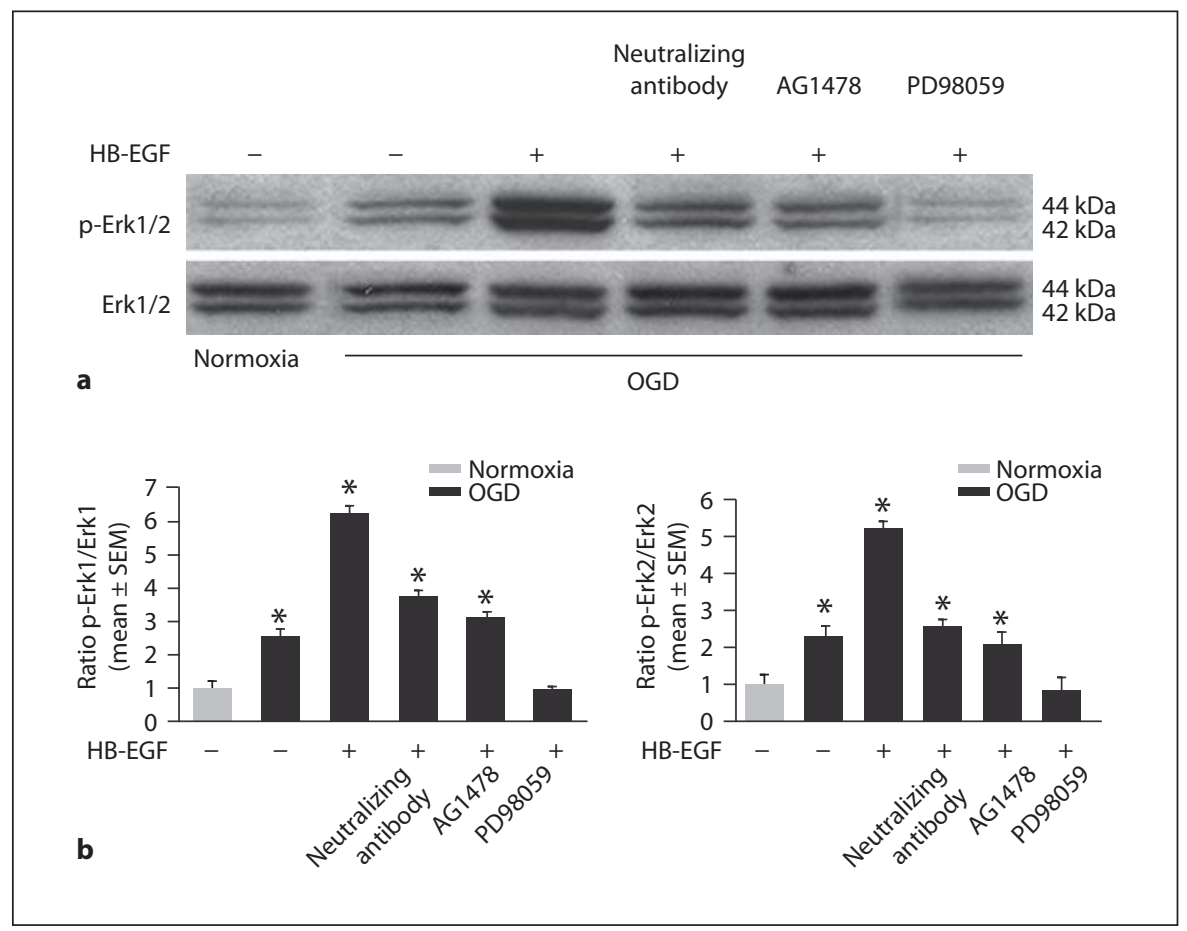

activation was induced within $1 \mathrm{~min}$ and lasted for at least $2 \mathrm{~h}$, a pattern that matches the sustained activation of Erk1/2. These results suggest that HB-EGF activates Ras and Rap1, leading to the activation of Erk1/2 in PC12 cells.

\section{HB-EGF Increases MAPK Activation in PC12 Cells Exposed to OGD Injury}

MAPK activation promotes neuronal cell survival and inhibits apoptosis after ischemic injury [29, 42]. We next examined the ability of HB-EGF to activate the MAPK pathway by detecting phosphorylation of Erk1/2 in PC12 cells exposed to OGD injury. PC12 cells were exposed to OGD for $3 \mathrm{~h}$, followed by addition of glucose and renewal of normoxia for an additional $21 \mathrm{~h}$. Immnoblot analysis of protein extracts from PC12 cells $24 \mathrm{~h}$ after OGD injury revealed enhanced Erk1/2 phosphoration following addition of HB-EGF (fig. 4). The increase in Erk1/2 phosphoration induced by HB-EGF was suppressed by preincubation of HB-EGF with neutralizing anti-HB-EGF antibodies or by addition of AG1478 (EGFR inhibitor) or PD98059 (MAPK inhibitor). These results show that HB-EGF is able to activate the MAPK pathway in PC12 cells even in an environment of neuronal cell injury. Notably, the protective effect of HB-EGF on injured PC12 cells is specific and EGFR dependent.

HB-EGF Is a Potent Neurotrophic Factor for PC12 Cells

\section{HB-EGF Promotes Cell Survival after OGD Injury}

HB-EGF significantly increased the viability of PC12 cells exposed to OGD injury compared to untreated cells, as determined by the MTT assay (fig. 5a). Addition of AG1478 or PD98059 suppressed the HB-EGF-mediated neuroprotective effects. Under conditions of cellular necrosis or apoptosis, cells lose cell membrane stabilization and thereafter release $\mathrm{LDH}$. We next quantified $\mathrm{LDH}$ leakage as a parameter of cell membrane integrity. LDH release was increased in PC12 cells subjected to OGD injury, whereas addition of HB-EGF to PC12 cells exposed to OGD injury led to decreased LDH release (fig. 5b). Again, AG1478 or PD98059 decreased the neuroprotective effects of HB-EGF.

\section{HB-EGF Decreases PC12 Cell Apoptosis after OGD Injury}

Apoptosis is the main process involved in OGD-induced cell death in PC12 cells. We next examined the effect of HB-EGF on PC12 cell apoptosis upon exposure of the cells to OGD injury. HB-EGF was added to cultured PC12 cells $16 \mathrm{~h}$ prior to OGD injury. After $3 \mathrm{~h}$ of OGD and $21 \mathrm{~h}$ of return to normal glucose and oxygen levels, HB-EGF significantly decreased the percentage of apoptotic cells compared with untreated control cells (20.9 \pm 5.9 vs. $45.4 \pm 4.67 ; \mathrm{p}<0.01$ ) (fig. 6). Addition of PD98059 


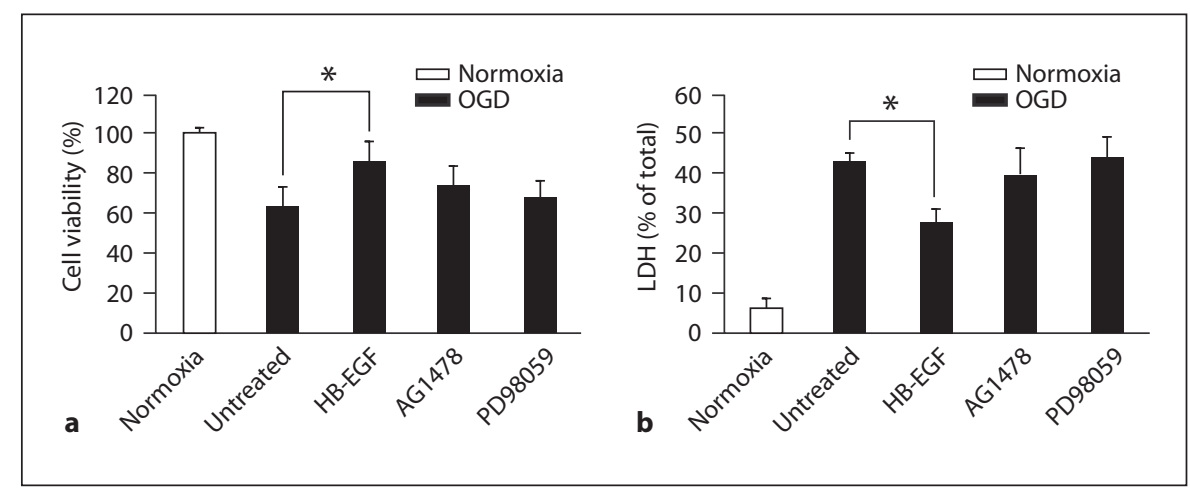

Fig. 5. Neuroprotective effect of HB-EGF on PC12 cells exposed to OGD. a Cell survival was analyzed by MTT assay to quantify surviving PC12 cells after $3 \mathrm{~h}$ of OGD injury and $21 \mathrm{~h}$ of return to normal glucose and oxygen levels. b Cell death was measured by $\mathrm{LDH}$ (\% of total) release into the medium after OGD injury. Cells treated with HB-EGF $(20 \mathrm{ng} / \mathrm{ml})$ had the growth factor added $16 \mathrm{~h}$ prior to and during OGD injury. Cells that received AG1478 or PD98059 had the inhibitors added 30 min prior to HB-EGF addition. The experiment was repeated three times with similar results. ${ }^{*} \mathrm{p}<0.05$. completely abolished the neuroprotective effects of HBEGF, while AG1478 partially blocked HB-EGF-mediated neuroprotection.

\section{Discussion}

HB-EGF is highly enriched in the brain and specifically induces cortical neuronal migration during the development of the brain [43]. Moreover, HB-EGF has been shown to exert several direct and indirect trophic actions in the central nervous system $[23,44]$. Recent evidence suggests an important role for HB-EGF in the development of the central nervous system and in neurogenesis; however, little is known about its direct effects on neurite outgrowth in PC12 cells. We used PC12 cells as a model system for neurite outgrowth, and found that HB-EGF induces neurite extension from PC12 cells in a dose-dependent manner. MAP1b, a developmentally regulated microtubule protein and neuronal cell differentiation marker, was robustly enhanced after HB-EGF treatment. HB-EGF treatment of PC12 cells led to a rapid increase in phosphorylated Erk1/2 levels within 5 min and prolonged Erk1/2 phosphorylation for at least $2 \mathrm{~h}$. Ras and Rap1 have been reported to be involved in NGF-mediated transient and sustained activation of Erk1/2. Similar to NGF, HBEGF triggers prompt Ras activation and increases Rap1 activation. Neurite outgrowth is always accompanied by the activation of the Erk $1 / 2$ cascade, as this is involved in the reorganization of microtubules towards the future direction of neurite outgrowth [45]. MAPK inhibition com- pletely blocked HB-EGF-mediated neurite outgrowth, confirming that activation of the MAPK signaling pathway is essential in HB-EGF-induced neurite outgrowth. In addition, EGFR blockade but not Trk A tyrosine kinase receptor blockade blunted the neurite extension effect of HB-EGF, indicating that HB-EGF-mediated neurite outgrowth is EGFR dependent. Considering that NGF-mediated neurite outgrowth is dependent upon Trk A tyrosine kinase receptor activation, we believe that the actions of HB-EGF and NGF on PC12 cells are mediated by distinct upstream receptors but share the downstream MAPK signaling pathway.

HB-EGF binds to cell surface heparan sulfate proteoglycans and interacts with EGFR on cell membranes to exert cryoprotective effects for many cell types [46, 47]. Moreover, HB-EGF forms complexes with other membrane proteins including CD9 [9] and integrin $\alpha 3 \beta 1$ [10], which enhance its biological activity. In addition, through binding to chondroitin sulfate-E, HB-EGF has been shown to promote neurite outgrowth in rat embryonic cortex neurons, an effect that was not observed with EGF [48]. Recent evidence has shown that HB-EGF is expressed at much higher levels than EGF in the central nervous system [49], indicating that HB-EGF may serve as a major ligand for the EGFR in neuronal cells. We found that HB-EGF significantly enhanced neurite outgrowth and induced sustained activation of the Erk signaling pathway, which has never been reported for EGF. These findings suggest that HB-EGF may have more potent effects compared with EGF on the promotion of neurite outgrowth, a very important morphological change 


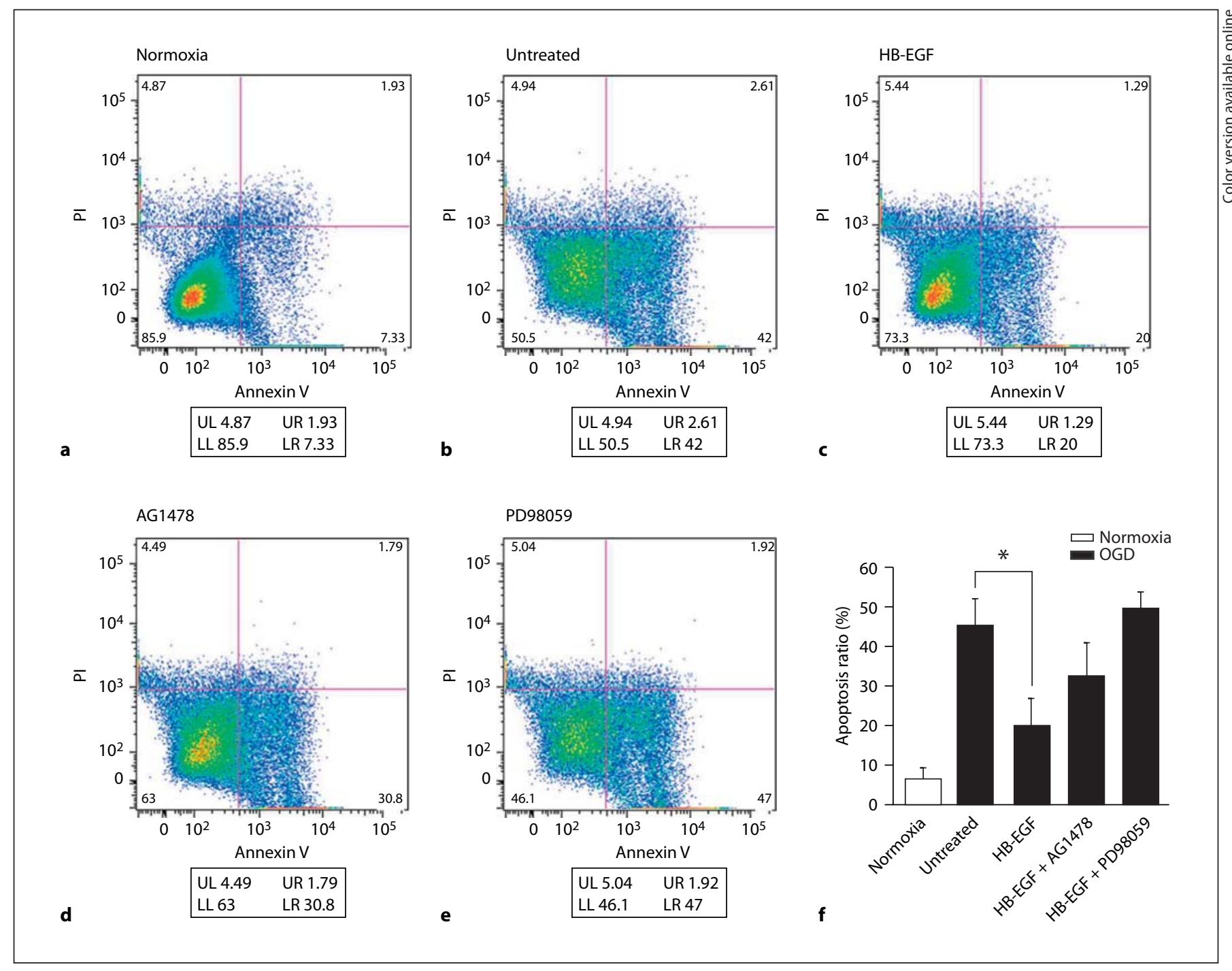

Fig. 6. Effect of HB-EGF on OGD-induced apoptosis in PC12 cells. Cells were harvested immediately after $3 \mathrm{~h}$ of OGD injury followed by $21 \mathrm{~h}$ of return to normal glucose and oxygen levels. Aliquots of $10^{6}$ cells/sample were simultaneously stained for FITC-annexin V and PI. Aliquots of $5 \times 10^{4}$ cells were analyzed by FACS, with results displayed as a bivariate distribution of annexin V and PI fluorescent intensity. Cells were grown under normal glucose/oxygen concentration (a), or were exposed to OGD (b-e). b Untreated cells. c HB-EGF-treated cells. d Cells that received AG1478 (EGFR inhibitor) 30 min prior to HB-EGF treat-

in synaptic formation during central nervous system development and postinjury axon path finding. ErbB4 is another transmembrane receptor for HB-EGF, and enhancement of ErbB4 expression has been reported to promote neurite outgrowth [50]. We found that ErbB4 expression was undetectable in both control and HB-EGF- ment. e Cells that received PD98059 (MAPK inhibitor) $30 \mathrm{~min}$ prior to HB-EGF treatment. Cells in the lower-left quadrant (LL), unstained for either annexin V or PI, represent viable uninjured cells; cells in the lower right quadrant (LR), stained for annexin $\mathrm{V}$ but not for PI, represent cells in the early or middle stages of apoptosis; cells in the upper-right quadrant (UR), positive for both annexin and PI, represent later apoptotic or necrotic cells. The percentage of cells in each quadrant is shown at the bottom of each corresponding panel. f Quantification of apoptotic cells. ${ }^{*} \mathrm{p}<0.01$ vs. untreated cells. treated PC12 cells by immunocy tochemistry and Western blotting in our studies (data not shown). This observation is in agreement with previous reports that PC12 cells do not express ErbB4 [51], and therefore the role of ErbB4 in HB-EGF-induced PC12 neurite outgrowth can be excluded. 
In addition to the effect of HB-EGF on PC12 cell differentiation, we also observed neurotrophic effects of HBEGF in injured PC12 cells. Ischemic injury was mimicked by a OGD using a special device. HB-EGF-treated PC12 cells had increased cell viability with decreased apoptosis and decreased LDH release in the face of OGD injury. The EGFR blocker AG1478 partially compromised HB-EGF neuroprotection, while the MAPK inhibitor PD98059 nearly completely blocked the neuroprotective effect of HB-EGF against OGD insult. These results suggest that MAPK is a critical signaling pathway in HB-EGF-mediated neuroprotection and that the EGF receptor is only partially involved in the protection against OGD insult. HBEGF binds directly to the antiapoptotic BAG-1 protein which may function as an alternative pathway used by HB-EGF to protect injured neuronal cells. In this study, we show that OGD causes PC12 death via apoptosis whereas OGD kills cortical neurons mostly via necrosis. Previous findings indicated that the survival-promoting effect of HB-EGF on cultured cortical neuronal cells was dependent upon astrocyte proliferation, and that this effect was possibly exerted through Erk1/2 [14]. We believe that the Erk1/2 pathway is a central mechanism used by HB-EGF to elicit a broad spectrum of biological activities, including cell survival and neurite outgrowth.

In conclusion, HB-EGF has been demonstrated to induce neuronal cell differentiation and to promote neuronal cell survival through the Erk signaling pathway. We have previously shown that deletion of the HB-EGF gene leads to neuronal degeneration in the enteric nervous system [unpublished data]. Based on this, we propose a role of HB-EGF in the development of the enteric nervous system and in neural network formation. In vivo studies are being developed in our laboratory to examine the ability of HB-EGF to protect the enteric nervous system from intestinal insults associated with disease processes such as intestinal ischemia/reperfusion injury or necrotizing enterocolitis.

\section{Acknowledgements}

This work was supported by grants R01 DK65306, R01 GM61193 and R01 DK074611 from the National Institutes of Health (G.E.B.).

\section{References}

1 Besner G, Higashiyama S, Klagsbrun M: Isolation and characterization of a macrophagederived heparin-binding growth factor. Cell Regul 1990;1:811-819.

- Higashiyama S, Abraham JA, Miller J, Fiddes JC, Klagsbrun M: A heparin-binding growth factor secreted by macrophage-like cells that is related to EGF. Science 1991;251:936-939.

-3 Goishi K, Higashiyama S, Klagsbrun M, Nakano N, Umata T, Ishikawa M, Mekada E, Taniguchi N: Phorbol ester induces the rapid processing of cell surface heparin-binding EGF-like growth factor: conversion from juxtacrine to paracrine growth factor activity. Mol Biol Cell 1995;6:967-980.

-4 Raab G, Higashiyama S, Hetelekidis S, Abraham JA, Damm D, Ono M, Klagsbrun M: Biosynthesis and processing by phorbol ester of the cell surface-associated precursor form of heparin-binding EGF-like growth factor. Biochem Biophys Res Commun 1994;204: 592-597.

5 Chobotova K, Muchmore ME, Carver J, Yoo HJ, Manek S, Gullick WJ, Barlow DH, Mardon HJ: The mitogenic potential of heparinbinding epidermal growth factor in the human endometrium is mediated by the epidermal growth factor receptor and is modulated by tumor necrosis factor- $\alpha$. J Clin Endocrinol Metab 2002;87:5769-5777.

-6 Elenius K, Paul S, Allison G, Sun J, Klagsbrun M: Activation of HER4 by heparinbinding EGF-like growth factor stimulates chemotaxis but not proliferation. ЕMBO J 1997;16:1268-1278.

7 Nishi E, Prat A, Hospital V, Elenius K, Klagsbrun $\mathrm{M}$ : $\mathrm{N}$-arginine dibasic convertase is a specific receptor for heparin-binding EGFlike growth factor that mediates cell migration. ЕMBO J 2001;20:3342-3350.

${ }_{8}$ Shishido Y, Sharma KD, Higashiyama S, Klagsbrun M, Mekada E: Heparin-like molecules on the cell surface potentiate binding of diphtheria toxin to the diphtheria toxin receptor/membrane-anchored heparinbinding epidermal growth factor-like growth factor. J Biol Chem 1995;270:29578-29585.

-9 Iwamoto R, Higashiyama S, Mitamura T, Taniguchi N, Klagsbrun M, Mekada E: Heparin-binding EGF-like growth factor, which acts as the diphtheria toxin receptor, forms a complex with membrane protein DRAP27/ CD9, which upregulates functional receptors and diphtheria toxin sensitivity. EMBO J 1994;13:2322-2330.

10 Nakamura K, Iwamoto R, Mekada E: Membrane-anchored heparin-binding EGF-like growth factor (HB-EGF) and diphtheria toxin receptor-associated protein (DRAP27)/ CD9 form a complex with integrin $\alpha 3 \beta 1$ at cell-cell contact sites. J Cell Biol 1995;129: 1691-1705.

-11 Lin J, Hutchinson L, Gaston SM, Raab G, Freeman MR: BAG-1 is a novel cytoplasmic binding partner of the membrane form of heparin-binding EGF-like growth factor: a unique role for proHB-EGF in cell survival regulation. J Biol Chem 2001;276:3012730132.

12 Hirokawa M, Miura S, Kishikawa H, Yoshida H, Nakamizo H, Higuchi H, Nakatsumi RC, Suzuki H, Saito H, Ishii H: Loading of mechanical pressure activates mitogen-activated protein kinase and early immediate gene in intestinal epithelial cells. Dig Dis Sci 2001; 46:1993-2003.

13 Nakagawa T, Sasahara M, Hayase Y, Haneda M, Yasuda H, Kikkawa R, Higashiyama S, Hazama F: Neuronal and glial expression of heparin-binding EGF-like growth factor in central nervous system of prenatal and earlypostnatal rat. Brain Res Dev Brain Res 1998; 108:263-272.

14 Farkas LM, Krieglstein K: Heparin-binding epidermal growth factor-like growth factor (HB-EGF) regulates survival of midbrain dopaminergic neurons. J Neural Transm 2002;109:267-277.

15 Cribbs RK, Harding PA, Luquette MH, Besner GE: Endogenous production of heparin-binding EGF-like growth factor during murine partial-thickness burn wound healing. J Burn Care Rehabil 2002;23:116-125.

16 Jin K, Mao XO, Sun Y, Xie L, Jin L, Nishi E, Klagsbrun M, Greenberg DA: Heparin-binding epidermal growth factor-like growth factor: hypoxia-inducible expression in vitro and stimulation of neurogenesis in vitro and in vivo. J Neurosci 2002;22:5365-2373. 
17 Homma T, Sakai M, Cheng HF, Yasuda T, Coffey RJ Jr, Harris RC: Induction of heparin-binding epidermal growth factor-like growth factor mRNA in rat kidney after acute injury. J Clin Invest 1995;96:10181025.

- 18 Frank GD, Mifune M, Inagami T, Ohba M, Sasaki T, Higashiyama S, Dempsey PJ, Eguchi S: Distinct mechanisms of receptor and nonreceptor tyrosine kinase activation by reactive oxygen species in vascular smooth muscle cells: role of metalloprotease and protein kinase C $\delta$. Mol Cell Biol 2003;23:15811589.

19 Kayanoki Y, Higashiyama S, Suzuki K, Asahi M, Kawata S, Matsuzawa Y, Taniguchi N: The requirement of both intracellular reactive oxygen species and intracellular calcium elevation for the induction of heparin-binding EGF-like growth factor in vascular endothelial cells and smooth muscle cells. Biochem Biophys Res Commun 1999;259: 50-55.

20 Tokumaru S, Higashiyama S, Endo T, Nakagawa T, Miyagawa JI, Yamamori K, Hanakawa Y, Ohmoto H, Yoshino K, Shirakata Y, Matsuzawa Y, Hashimoto K, Taniguchi N: Ectodomain shedding of epidermal growth factor receptor ligands is required for keratinocyte migration in cutaneous wound healing. J Cell Biol 2000;151:209-220.

-21 McCarthy DW, Downing MT, Brigstock DR, Luquette MH, Brown KD, Abad MS, Besner GE: Production of heparin-binding epidermal growth factor-like growth factor (HBEGF) at sites of thermal injury in pediatric patients. J Invest Dermatol 1996;106:49-56.

-22 Sugiura S, Kitagawa K, Tanaka S, Todo K, Omura-Matsuoka E, Sasaki T, Mabuchi T, Matsushita K, Yagita Y, Hori M: Adenovirusmediated gene transfer of heparin-binding epidermal growth factor-like growth factor enhances neurogenesis and angiogenesis after focal cerebral ischemia in rats. Stroke 2005;36:859-864.

-23 Jin K, Sun Y, Xie L, Childs J, Mao XO, Greenberg DA: Post-ischemic administration of heparin-binding epidermal growth factorlike growth factor (HB-EGF) reduces infarct size and modifies neurogenesis after focal cerebral ischemia in the rat. J Cereb Blood Flow Metab 2004;24:399-408.

24 Jacobs JR, Stevens JK: Dynamics of behaviour during neuronal morphogenesis in culture. Cell Motil Cytoskeleton 1987;8:250-260.

-25 Fabian Z, Vecsernyes M, Pap M, Szeberenyi $\mathrm{J}$ : The effects of a mutant $\mathrm{p} 53$ protein on the proliferation and differentiation of PC12 rat phaeochromocytoma cells. J Cell Biochem 2006;99:1431-1441.

26 Hughes AL, Messineo-Jones D, Lad SP, Neet KE: Distinction between differentiation, cell cycle, and apoptosis signals in PC12 cells by the nerve growth factor mutant $\delta 9 / 13$, which is selective for the p75 neurotrophin receptor. J Neurosci Res 2001;63:10-19.
Kim HS, Yumkham S, Kim SH, Yea K, Shin YC, Ryu SH, Suh PG: Secretin induces neurite outgrowth of PC12 through cAMP-mitogen-activated protein kinase pathway. Exp Mol Med 2006;38:85-93.

28 Williams TM, Ndifor AM, Near JT, ReamsBrown RR: Lead enhances NGF-induced neurite outgrowth in $\mathrm{PC} 12$ cells by potentiating ERK/MAPK activation. Neurotoxicology 2000;21:1081-1089.

29 Bonni A, Brunet A, West AE, Datta SR, Takasu MA, Greenberg ME: Cell survival promoted by the Ras-MAPK signaling pathway by transcription-dependent and -independent mechanisms. Science 1999a;286:13581362.

30 Uwabe K, Matsumoto M, Nagata K: Monokine induced by interferon- $\gamma$ acts as a neurotrophic factor on $\mathrm{PC} 12$ cells and rat primary sympathetic neurons. J Biol Chem 2005;280: 34268-34277.

31 Kyoto A, Hata K, Yamashita T: Synapse formation of the cortico-spinal axons is enhanced by RGMa inhibition after spinal cord injury. Brain Res 2007;1186:74-86.

32 Keating HH, Asai DJ: Distribution of phosphorylated microtubule-associated protein $1 \mathrm{~B}$ during neurite outgrowth in PC12 cells. Dev Biol 1994;162:143-153.

33 Goold RG, Gordon-Weeks PR: Microtubuleassociated protein $1 \mathrm{~B}$ phosphorylation by glycogen synthase kinase $3 \beta$ is induced during PC12 cell differentiation. J Cell Sci 2001; 114:4273-4284.

34 Fischer I, Romano-Clarke G: Association of microtubule-associated protein (MAP1B) with growing axons in cultured hippocampal neurons. Mol Cell Neurosci 1991;2:3951.

35 Mansfield SG, Diaz-Nido J, Gordon-Weeks PR, Avila J: The distribution and phosphorylation of the microtubule-associated protein MAP 1B in growth cones. J Neurocytol 1991; 20:1007-1022.

-36 Patapoutian A, Reichardt LF: Trk receptors: mediators of neurotrophin action. Curr Opin Neurobiol 2001;11:272-280.

-37 Morishima-Kawashima M, Kosik KS: The pool of map kinase associated with microtubules is small but constitutively active. Mol Biol Cell 1996;7:893-905.

38 Goold RG, Gordon-Weeks PR: The MAP kinase pathway is upstream of the activation of GSK3 $\beta$ that enables it to phosphorylate MAP1B and contributes to the stimulation of axon growth. Mol Cell Neurosci 2005;28: 524-534.

39 Peraldi P, Scimeca JC, Filloux C, Van Obberghen E: Regulation of extracellular signalregulated protein kinase-1 (ERK-1; pp44/ mitogen-activated protein kinase) by epidermal growth factor and nerve growth factor in PC12 cells: implication of ERK1 inhibitory activities. Endocrinology 1993;132:25782585.
40 Powers JF, Shahsavari M, Tsokas P, Tischler AS: Nerve growth factor receptor signaling in proliferation of normal adult rat chromaffin cells. Cell Tissue Res 1999;295:21-32.

-41 York RD, Yao H, Dillon T, Ellig CL, Eckert SP, McCleskey EW, Stork P J: Rapl mediates sustained MAP kinase activation induced by nerve growth factor. Nature 1998;392:622626.

42 Bonni A, Brunet A, West AE, Datta SR, Takasu MA, Greenberg ME: Cell survival promoted by the Ras-MAPK signaling pathway by transcription-dependent and -independent mechanisms. Science 1999b;286:13581362.

43 Zhou Y, Pernet V, Hauswirth WW, Di Polo A: Activation of the extracellular signal-regulated kinase $1 / 2$ pathway by AAV gene transfer protects retinal ganglion cells in glaucoma. Mol Ther 2005;12:402-412.

-44 Nakagawa T, Sasahara M, Hayase Y, Haneda M, Yasuda H, Kikkawa R, Higashiyama S, Hazama F: Neuronal and glial expression of heparin-binding EGF-like growth factor in central nervous system of prenatal and earlypostnatal rat. Brain Res Dev Brain Res 1998; 108:263-272.

45 Kornblum HI, Zurcher SD, Werb Z, Derynck R, Seroogy KB: Multiple trophic actions of heparin-binding epidermal growth factor (HB-EGF) in the central nervous system. Eur J Neurosci 1999;11:3236-3246.

46 Tie L, Zhang JZ, Lin YH, Su TH, Li YH, Wu HL, Zhang YY, Yu HM, Li XJ: Epinephrine increases phosphorylation of MAP-2c in rat pheochromocytoma cells (PC12 cells) via a protein kinase $\mathrm{C}$ - and mitogen-activated protein kinase-dependent mechanism. J Proteome Res 2008;7:1704-1711.

47 Paria BC, Elenius K, Klagsbrun M, Dey SK: Heparin-binding EGF-like growth factor interacts with mouse blastocysts independently of ErbB1: a possible role for heparan sulfate proteoglycans and ErbB4 in blastocyst implantation. Development 1999;126:19972005.

48 Higashiyama S, Abraham JA, Klagsbrun M: Heparin-binding EGF-like growth factor stimulation of smooth muscle cell migration: dependence on interactions with cell surface heparan sulfate. J Cell Biol 1993;122:933940.

49 Deepa SS, Umehara Y, Higashiyama S, Itoh N, Sugahara K: Specific molecular interactions of oversulfated chondroitin sulfate $\mathrm{E}$ with various heparin-binding growth factors. Implications as a physiological binding partner in the brain and other tissues. J Biol Chem 2002;277:43707-43716.

-50 Hayase Y, Higashiyama S, Sasahara M, Amano S, Nakagawa T, Taniguchi N, Hazama F: Expression of heparin-binding epidermal growth factor-like growth factor in rat brain. Brain Res 1998;784:163-178.

51 Vaskovsky A, Lupowitz Z, Erlich S, PinkasKramarski R: ErbB-4 activation promotes neurite outgrowth in PC12 cells. J Neurochem 2000;74:979-987. 